\title{
Why You and Your Students will both Fall in Love with Decision Experiments in Class
}

\author{
让三尺讲堂㝋育出大千世界： \\ 如何在课堂里巧妙运用模拟决策实验
}

Darren Weng 翁祉泉*

$\mathrm{H}$ AVE you ever thought of using decision experiments, a student-centered, interactive way, to spice up your classroom? After many years of conducting experiments in my introductory and higher-level economics classes, I have found this approach to be highly conducive to enhancing student motivation and academic performance. In this short article I am going to illustrate a number of pedagogical advantages of using classroom decision experiments, as well as offer a few practical tips for faculty interested in incorporating these active learning elements into their classrooms.

如果你曾经为自己的教学内容太过抽象不够有趣而烦恼, 你 有没有设想过在你的课堂里通过 “做实验” 来提升学生的学习主 动性和兴趣? 当然, 这类实验并不依靠化学反应或者生物显微 镜, 而是会把大千世界里的各种社会现象和经济激励模拟成可以 在课堂里执行的简单决策。在参与实验的过程和之后对实验结果 的分析中, 学生将成为知识的生产者而不仅仅是接受者。多年在 课堂里和学生一起模拟决策实验的经验告诉我, 一方面课堂决策 实验对于提高教学效果的益处良多, 另一方面这种方法却少为人 知。在这篇短文里, 我会和大家分享课堂决策实验的众多优点, 同时也会提供若干关于如何设计和执行实验并能使之和课堂教学 有机结合的个人建议。

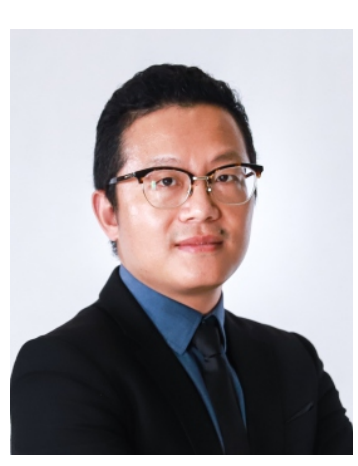

* Dr Darren Weng, Assistant Professor of UIC's Division of Business and Management, Programme Director of eBusiness Management and Information Systems, winner of 2018-2019 President's Award for Teaching and Service for Academic Staff.

翁祉泉博士, 北师港浸 大工商管理学部助理教 授, 电子商务与资讯系 统管理专业课程主 任, 2018-2019学年 “杰 出教学与服务奖” 获得 者。 
$\mathrm{M}$ $Y$ belief in teaching is that knowledge is to be discovered, rather than to be transferred. Even though I may have taught a certain subject countless times, I never consider myself an expert in it. Instead, I think of myself as just another novice like my own students who are coming across the materials for the very first time. Every time I walk into my classroom, I share the air of unease and eagerness with my students. "What are we going to learn in this new chapter? Is it directly related to the last chapter which I did not understand so well? What does this uninteresting and theoretical topic have to do with my future career and my life in general? How do these theories help us connect to the real world?"

Since the study of economics is often called "the dismal science" as it tries to explain human behaviors in a sometimes convoluted way, all of the above questions are legitimate concerns that an instructor must strive to answer if he wants to keep his students interested and motivated. They are also the same set of questions that I challenge myself to make clear to my students by the end of each lecture.

\section{Why are behavioral and decision experiments such a valuable tool in the classroom?}

To me, the secret ingredient to successfully leading my students onto an exciting, self-guided journey of new knowledge discovery is the organic integration of classroom-based behavioral or decision experiments ("BDE" henceforth) into my lectures. By allowing students to take greater responsibility in the knowledge discovery process, this student-centered, interactive approach has done great marvels in improving student learning outcomes in many of my economics classes.

A carefully designed classroom-based BDE has two defining features: First, students need to make active decisions on behalf of themselves as individuals, or on behalf of a group, in a real life decision environment distilled into a classroom setting. The structure and the parameters of the problem must be explained in simple terms and in a short amount of time. Second, the decisions entailed in the experiments must embody the essence of the theories and principles to be presented in the subsequent main lecture.

All sorts of economic environments can be studied using classroom experiments including bargaining, risky decision making, buying and selling in markets, cartel behavior, contributions to public goods, taxes, production with negative externalities, international trade, general macroeconomic equilibrium and many more.

Classroom decision experiments present a unique setting for students to experience the economic incentives and forces at work on a first-person basis. Unlike in experiments in natural sciences such as chemistry or biology, student 
participants in BDEs produce a rich amount of empirical data via their own personal behaviors or decisions. Students are literally the owner of the observations and the behavioral regularities from the experiment, and thus, it is much easier for them to relate to the new idea and knowledge that is generated. In a sense, they have become the entrepreneurs in the production of knowledge in class.

Conversely, the role of the instructor has been transformed from a "teacher" asserting truth and relevance to that of a "scientific observer" guiding students in testing the validity of the new theories they have freshly formulated as a result of inductive, evidence-based learning.

In my class, the observations from experiments often provoke intense scrutiny and heated discussion among my students, because they inevitably exhibit a surprising diversity of behavioral patterns. While some of the results demonstrate very directly to the students the basic incentives involved in being a buyer, seller, producer, taxpayer, policymaker, deal-maker, or whatever other roles they may assume, students often remember the mistakes, biases, social dynamics and other subtle aspects of the behaviors in the experiments that would be impossible to glean from formal models or accounts in their textbook. Moreover, their eyes would glitter with excitement when they see how varied decisions could have translated into an entirely different set of social outcomes.
For example, the concept of "irrational exuberance" was so intricately difficult to explain to students until they had experienced it first-hand in an experimental asset-price market in which they find themselves trading the asset at exorbitantly high price - far off its fundamental value - even in the last few periods before the market for the asset would completely collapse. Simple experiments often have tremendous power in convincing students of the importance and shortfall of certain assumptions, the rigor of control needed in establishing causal relations between economic variables, and most importantly, the potential gaps between theory and practice.

Time and again, I have found that classroom experiments have a strong, stimulative effect on student learning, as they retain the knowledge better and develop a more critical mindset in the long run. Just as factory workers become more proficient and corporate employees become more knowledgeable as they perform their tasks, independent learning and deeper understanding are fostered as students immerse themselves in "learning by doing" when they evaluate the problems and are making choices in the experiment. The knowledge is retained more strongly also because it results from being convinced about the usefulness of an otherwise abstract economic theory. Plenty of scholarly research has shown that participation in classroom experiments leads to improvement in academic 
performances (Emerson \& Taylor, 2004;

Ball et al., 2006; Durham et al., 2007).

Classroom experiment also turns out to be a great motivator. Anecdotes has it that Vernon Smith, the Nobel Laureate in Economics in 2002, whose many contributions include developing experimental economics into a widely accepted research paradigm, was originally motivated by his experience as a PhD student participating in market experiments carried out by his Harvard professor Edward Chamberlin. It is also worth noting that the author of this article chose to become an economist partly because of his participation in economic research experiments as an undergraduate student many years ago.

\section{A few tips on the design and implementation of a successfully run classroom experiment}

As my own research uses experimental and behavioral methods in studying economic decision-making, I enjoy adapting some of the research techniques for interesting pedagogical applications. For example, in my microeconomics and industrial organizations classes, I illustrated the relationship between consumer values and market demand by engaging students in a real-time auction from a copy of the textbook I own. Students also get to experience the differential effects from the division of labour and diminishing marginal productivity up close by performing simple, simulated production tasks in competitive teams in class. They also experienced asset bubbles and financial crisis in a computerized financial trading market. Students in public-goods experiments learned the crucial concept of market failure and searched vehemently for a solution.

Over the years, the experiences in running many successful and even more not-sosuccessful experiments in classrooms have taught me a few perpetually useful tips which I would like to share with those interested. The hope is to help you avoid pitfalls and help your students learn more from the experiments:

- Preparation for the experiment and the follow-up lesson are likely to take more of your efforts (at least for the first time) and class time than delivering the same old lecture materials once again. So be prepared to challenge yourself to step outside your comfort zone.

- The same goes for your students: Student preparation is the key for effective participation and valid observations. Helping the students prepare for the experiment is key to them having a successful and enjoyable learning experience. A clear set of instructions is absolutely vital.

- One of the biggest fears for teachers who have never conducted a classroom experiment is "what if things don't go as 
planned." I can assure you that things will go wrong occasionally, but it is often the case that "failure" creates the most valuable learning opportunity.

- Get everyone in your class involved in the experiment. For example, you can divide the class into pairs for strategic decision experiments; you can hold an auction with everyone in the class as bidders; you can simulate production processes by having students organize into production teams; in other situations, you can break students into any number of groups and ask each group to discuss and submit a collective decision.

- Research experiments generally employ both control and treatment groups in order to infer causal relationship. In these cases, it is better to have your students form hypotheses in their mind before they embark on the experiment.

- "Debriefing" session following the experiment is a must: Just doing the experiment misses the larger picture. You need to guide students through the process of interpreting and learning from what happened. Once you collect the data, communicating the results to students and linking it to what they are learning in the main lecture is imperative. Follow up by asking students to explain their thought process and decision criteria verbally or in writing, and to interpret any gap between their decisions and those prescribed by theory.

- Finally, if you are crunched with time and energy to prepare for your own experiment and instead want one that is ready-made in the most efficient manner, there is GOOD NEWS for you: There are plenty of WEB-BASED EXPERIMENTS which students can simply log in with their laptops or mobile phones together with a session passcode handed out by you. The number of these experiment portals and the variety of experiments available are growing by the day. The added bonus is that data of these online experiments are automatically stored on the cloud and analyses and visuals are provided real-time with a few clicks. As a result you can retrieve all of the results and analyses and discuss with your class next time you meet.

Two such web-based experiment portal that I personally recommend are Mobile Laboratory at University of Chicago (www.moblab.com) and economicsgames.com. 


\section{Cases with Decision Experiments in Classroom}

$\mathrm{S}$ TUDENTS often keep a suspicious mind when they are told of a new theory or a new set of results, especially in areas with which they are unfamiliar, due to their limited life experiences. Nonetheless, in my class I encourage them to keep thinking critically all the time and ask probing questions such as: Does this theory work all the time, or only under a special set of circumstances? Why does the model assume that the power of one set of incentives dominates the other set? Will a corporate manager or a financial investor really behave as predicted, or will they depart from the behavior in a certain way? If I were to test these results in data, what types of variables and observable data will I need to collect and what are the possible hypotheses? Do I truly believe that the data will support it? Thankfully, some of these concerns can be readily addressed by running classroom decision experiments on the spot.

For instance, one of the important lessons students learn from firm theory in microeconomics is that the marginal productivity of a worker rises first and then falls eventually as the number of her co-workers increases. Although we try our best to explain to students that the initial rise in worker productivity is a result of specialization and cooperation among workers and that its eventual fall is inevitable because of the constraints posed by other fixed firm resources, students continue to find these concepts abstract and difficult to comprehend. Consequently, they would take these principles half-heartedly for the sake of taking the exam but forget them completely after the final exam. Thus, students can never really understand a theory and its nuanced complications until they have lived through it. So in this case, the question becomes: How can I get my students to experience worker specialization, cooperation, and firm resource constraints first-hand in the classroom?

To that purpose, I designed a decision experiment to be played by my students in class that simulates real-time firm production. The production task is simple, yet requires planning and cooperation: A team of "workers" needs to plant "TREE"s on the blackboards by writing as many capital-letter "T-R-E-E" as possible within 60 seconds in an encircled box known as "a farm field". To plant every 10 trees necessitates the workers to run towards the other end of the classroom to receive a card known as "a bucket of water". However, each 
time a worker succeeds in running from one end to the other end in the classroom, he or she can obtain only one bucket of water which helps to incentives more realistic, I also add the element of competition. At least two different teams compete with each other in this experiment, while higher output by one firm translates into more participation points. The experiment would run 15-20 minutes, and the number of workers assigned to each competitive team would go up from just one worker to 5 to 6 workers in the last round. After teams report and record their production outputs in each of the rounds, we design a table to compare worker's productivity of all of the teams in each of the rounds.

The students invariably found the experiment a fascinating learning experience about firm behaviors! First, students discover the need to divide themselves into several distinct roles: the planter, the runner, and the counter. Teams always try to strategize about how many each of these roles they should assign and who should do it. They also ask among themselves: Does it work more effectively if each worker assumes all three roles and therefore works independently? Or should we assign

roles for someone to specialize in and coordinate work outputs collectively? What are the basis of the desired assignment and coordination mechanism? What happen to average productivity if we "employ" more workers in the team? If the TREEs can be sold in the competitive market, what is the ideal number of workers to be employed?

At the beginning of each round, teams would often engage in lively discussion among themselves about possible ways to raise higher outputs, their discussion centering on the issue of how to specialize and cooperate among workers. Occasionally, there would be a round in which more workers would actually result in negative output gain. In some other instances, there would be a round with spectacular output growth. Then the team would collectively scrutinize what had just happened and try to come up with an alternative theory to explain it. To both my students and to me, it is so gratifying to see that a piece of economic theory would come alive right in front of our eyes - with both its realism and its flaws. After participating in the experiment, the students in my class would never forget about the economic dynamics governing marginal productivity. $\mathbb{Z}$ 